\title{
As classes sociais no Brasil: uma proposta de leitura relacional
}

Alexandre Aparecido dos Santos ${ }^{1}$

Resumo: Este artigo tem por objetivo apresentar uma leitura sobre alguns dos conceitos e das contribuições teóricas de Jessé Souza sobre os estudos das dinâmicas das classes sociais no país. De forma mais precisa, vamos apresentar e discutir a leitura de Jessé Souza sobre parte dos brasileiros que recentemente foram integrados a uma economia de mercado e conseguiram maior acesso a alguns bens de consumo. Nesse sentido, ao longo deste trabalho, discutiremos sobre questões da desigualdade social entre as classes sociais brasileiras, à luz dos escritos de Jessé Souza, realizando um cotejamento com a proposta teórica de Pierre Bourdieu, sobretudo no que diz respeito à ideia de um conhecimento praxiológico, no intuito de compreender as potencialidades dos conceitos e das noções cunhadas por Jessé Souza, diante da realidade contemporânea nacional e sua contribuição para o campo dos estudos sociológicos no país.

Palavras-chave: Classes sociais. Capital familiar. Abandono social. Habitus.

\section{Social classes in Brazil: a proposal for relational reading}

\begin{abstract}
This article aims to present a reading on some of the concepts and theoretical contributions of Jessé Souza on the studies of the dynamics of social classes in the country. More precisely, we will present and discuss Jessé Souza's reading about part of the Brazilians who have recently been integrated into a market economy and have gained greater access to some consumer goods. In this sense, throughout this work, we will discuss issues of social inequality between Brazilian social classes in the light of the writings of Jesse Souza, making a approximation with the theoretical proposal of Pierre Bourdieu, especially with regard to the idea of praxiological knowledge, in in order to understand the potential of the concepts and notions coined by Jessé Souza before the national contemporary reality and his contribution to the field of sociological studies in the country.
\end{abstract}

Keywords: Social classes. Family capital. Social abandonment. Habitus.

1 Doutorando (PPGCS/UNESP/Ar). Bolsista Capes DS. E-mail: alexandre.sociais@hotmail.com 


\section{Introdução}

Pensar sobre o Brasil, tendo em vista suas especificidades culturais, políticas e econômicas, sempre foi considerado um grande desafio, mas contemporaneamente pode se dizer que esse desafio ganhou proporções ainda maiores. Esse crescimento deve-se ao fato de que, nos últimos 30 anos, nosso país passou por inúmeras transformações sociais, especificamente no que diz respeito ao modo de vida que repercute na constituição das classes sociais.

Diante desse desafio interpretativo apresentado pela realidade social do Brasil contemporâneo, é possível encontrar, nos escritos de Jessé Souza, uma tentativa de construção de um novo entendimento sobre esse contexto, assim como das dinâmicas e transformações no interior das classes sociais brasileiras.

Neste artigo, a partir de um balanço teórico, apresentamos uma leitura sobre alguns dos apontamentos desse autor, sem a intenção de esgotar as discussões sobre o tema, sobre as dinâmicas das classes sociais no Brasil, mais precisamente, sobre parte da população nacional que recentemente viveu um processo de integração à economia de mercado, principalmente através da ampliação do acesso a alguns bens de consumo.

A primeira seção deste artigo apresenta uma discussão sobre a noção de abandono social e sua relação com o conceito de habitus primário, cunhado por Souza (2003). A seção se desenvolve em torno de como esse conceito resgata uma discussão iniciada por Joaquim Nabuco, no período das lutas abolicionistas, no final do império, e resgatada por Florestan Fernandes, em sua interpretação do processo de integração da população negra à economia de mercado e, assim, à sociedade nacional de classes. Na segunda seção, iniciamos uma discussão sobre a noção de capital familiar e seu papel na interpretação construída por Jessé Souza, sobre a diversidade e a dinâmica existente entre as classes sociais no Brasil.

Assim, ao longo deste trabalho, discutiremos sobre questões da desigualdade social entre as classes sociais brasileiras, à luz dos escritos de Jessé Souza, buscando realizar um cotejamento com a proposta teórica de Pierre Bourdieu, sobretudo no que diz respeito à ideia de um conhecimento praxiológico, no intuito de compreender as potencialidades dos conceitos e das noções cunhadas por Jessé Souza, diante da realidade contemporânea nacional e sua contribuição para avanços teóricos que estão para além de uma leitura economicista das relações sociais.

\section{O abandono social e o habitus primário}

Segundo Souza (2003), a maior parte das tentativas teóricas de entender e interpretar as especificidades socioculturais do povo brasileiro, quase sempre, esteve dentro de uma leitura economicista da realidade, guiada por uma crença no progresso econômico, pois entendia este como o único caminho possível para superação das questões de desigualdades sociais que assolam o país.

Para Souza (2003), essa crença existiria pelo menos desde o início do regime republicano no país e, segundo ele, seria a responsável por uma naturalização das desigualdades sociais que existem no país, desde o início da República: 
A ausência de uma adequada problematização dos aspectos de aprendizados coletivos morais e políticos envolvidos na questão da desigualdade e da sua naturalização e, consequentemente, na problemática da construção social da subcidadania, deve-se, também, creio eu, à complexa configuração do campo científico entre nós [...] parte-se de uma perspectiva culturalista sem adequada vinculação com a eficácia de instituições fundamentais, onde a "cultura" é percebida como uma entidade homogênea, totalizante e autorreferida. Seria por conta dessa soberania do passado sobre o presente que nos confrontamos com solidariedades verticais baseadas no favor, subcidadania para a maior parte da população e abismo material e valorativo entre as classes e as "raças" que compõem nossa sociedade. (SOUZA, 2003, p. 51)

Em sua leitura, essa perspectiva culturalista seria uma limitação teórica para o campo científico nacional e colocaria, diante dos pesquisadores brasileiros, a necessidade de construção de novos caminhos e modelos explicativos, que permitam um entendimento mais amplo no que diz respeito às dinâmicas sociais no Brasil.

Esses novos caminhos teóricos possibilitariam, ao campo científico nacional, avançar para além dos limites analíticos decorrentes do paradigma do fetichismo do progresso econômico. A necessidade dessa reformulação nos modelos teóricos seria uma demanda apresentada pelo próprio contexto social, já que, nas últimas décadas, o país vivenciou uma ampliação da participação de uma parcela da população em um mercado de bens de consumo. Nesse sentido essa limitação também seria política, pois, sem um entendimento satisfatório diante de uma realidade social, pouco se pode fazer no que diz respeito à esfera das políticas públicas, no sentido de transformar e melhorar essa realidade.

Diante desse quadro, Souza (2003) defende a ideia de que um entendimento sobre os aspectos socioculturais de manutenção da desigualdade no país hoje só se tornaria possível através de estudos sobre as condições culturais, políticas e econômicas pelas quais esse contexto de desigualdade se engendrou.

Essa busca por uma espécie de gênese desse contexto de desigualdade pode ser encontrada em seus escritos, quando Souza (2003) retoma uma discussão sobre a noção de "abandono social", apresentada no fim do século XIX, por Joaquim Nabuco (1997), e posteriormente desenvolvida por Florestam Fernandes (2008), já em meados do século passado:

O dado essencial de todo o processo de desagregação da ordem servil e senhorial foi, como nota corretamente Florestan, o abandono do liberto à própria sorte (ou azar). Os antigos senhores, na sua imensa maioria, o Estado, a Igreja, ou qualquer outra instituição, jamais se interessaram pelo destino do liberto. Este, imediatamente depois da abolição, se viu responsável por si e seus familiares, sem que dispusesse dos meios materiais ou morais para sobreviver numa nascente economia competitiva de tipo capitalista e burguês. (SOUZA, 2003, p. 54)

Em nossa leitura, essa noção de abandono social e seus desdobramentos seriam o alicerce para as interpretações e explicações apresentadas por Jessé Souza, sobre a produção e a manutenção do abismo social estabelecido pelo contexto de desigualdade social no país. A noção de abandono social pode ser percebida, por exemplo, na construção teórica do que Souza (2003) conceitua enquanto uma condição de sub-cidadania, como se pode ver: "A tese de Florestan é a de que a família negra não chega a se constituir como uma unidade capaz de exercer as suas virtualidades principais de modelação da personalidade básica e controle de comportamentos egoísticos. Existe aqui, nesse tema central da ausência da unidade familiar 
como instância moral e social básica, uma continuidade com a política escravocrata brasileira, que sempre procurou impedir qualquer forma organizada familiar ou comunitária da parte dos escravos". (SOUZA, 2003, p. 55).

No limite as desigualdades contemporâneas em nossa sociedade seriam o reflexo ou o resultado de uma histórica falta de ação por parte do Estado nacional, diante de algumas situações, como, por exemplo, a da população negra diante do fim do trabalho escravo, uma população que foi abandonada à própria sorte, sem trabalho, sem moradia, em meio a uma sociedade que, há mais de 300 anos, só via naquela população uma forma de mercadoria.

Nossa leitura sobre essa construção teórica de Jessé Souza aponta para alguns momentos em que Souza (2003) retoma as considerações de Florestam Fernandes (2008) sobre a integração ou não dos negros na sociedade de classes. Exemplo disso ocorre quando Souza afirma:

Esse aspecto é fundamental para meu argumento, na medida em que o que Florestan está pleiteando é, na realidade, a meus olhos, atribuir à constituição e reprodução de um habitus específico, no sentido de Bourdieu [...] Este ponto é central, posto que, se é a reprodução de um "habitus precário" a causa última da inadaptação e marginalização desses grupos, então o problema não é "meramente a cor da pele", como certas tendências empiricistas acerca da desigualdade brasileira tendem, hoje, a interpretar. (SOUZA, 2003, p. 56)

O argumento aqui apresentado é que a noção de abandono social tem um lugar central nas interpretações e explicações que Souza elabora sobre as desigualdades sociais em nosso país. Nosso argumento se sustenta em passagens como esta:

[...] é precisamente o abandono secular do negro e do dependente de qualquer cor à própria sorte, a "causa" óbvia de sua inadaptação. Foi esse abandono que criou condições perversas de eternização de um "babitus precário", que constrange esses grupos a uma vida marginal e humilhante à margem da sociedade incluída (SOUZA, 2003, p. 57).

Nesse sentido, Souza $(2003,2004)$ busca estabelecer um novo paradigma explicativo sobre o contexto contemporâneo de desigualdade no país. Esse paradigma, em nossa leitura, se fundamentaria em dois aspectos: a busca por superar o limite das explicações pautadas no que ele nomeia de uma "[...] crença "fetichista" no progresso econômico, que faz esperar da expansão do mercado a resolução de todos os nossos problemas sociais" (SOUZA, 2003, p. 51) e a retomada das questões sobre o abandono social, tendo em vista seus desdobramentos contemporâneos.

Dessa forma, Souza $(2003 ; 2004)$ propõe um novo modo de olhar para o quadro contemporâneo da desigualdade entre as classes sociais brasileiras. Ele apresenta, como ponto de partida, uma apropriação do conceito filosófico de habitus: "uma noção antiga, proveniente de Aristóteles, retomada por São Tomás de Aquino e pela corrente sociológica de Weber e Durkheim" (DOSSE, 1994, p. 338). Em Bourdieu (1983), tal conceito ganha um sentido prático, uma vez que seria $\mathrm{o}$

[...] produto do trabalho de inculcação e de apropriação necessário para que esses produtos da história coletiva, que são as estruturas objetivas (por exemplo, da língua, da economia etc.), consigam reproduzir-se, sob a forma de disposições duráveis, em todos os organismos (que podemos, se quisermos, chamar indivíduos) duravelmente submetidos aos mesmos condicionamentos, colocados, portanto, nas mesmas condições materiais de existência (BOURDIEU, 1983, p. 78). 
Esse sentido prático dado ao conceito, por Pierre Bourdieu, ganha um uso analítico próprio na proposta interpretativa de Jessé Souza:

Esse conceito, ao contrário da tradição racionalista e intelectualista, permite enfatizar todo o conjunto de disposições culturais e institucionais que se inscrevem no corpo e que se expressam na linguagem corporal de cada indivíduo, transformando, por assim dizer, as escolhas valorativas culturais e institucionais em carne e osso (SOUZA, 2004, p. 85).

Esse caráter analítico com o qual Jessé Souza operacionaliza o conceito diz respeito a uma categorização de instâncias do habitus. É através dessas instâncias que Souza (2004) categoriza a diversidade de dinâmicas e pertencimentos sociais existentes entre as classes sociais brasileiras:

Assim, proponho uma subdivisão à categoria de habitus, de tal modo a lhe conferir um caráter histórico mais matizado, acrescentando, portanto, uma dimensão genética e diacrônica à temática de sua constituição. Assim, em vez de utilizar o conceito de babitus genericamente, aplicando-o a situações específicas de classe num contexto sincrônico, como faz Bourdieu, talvez seja mais profícuo se pensar em uma pluralidade de habitus. Se para o indivíduo o habitus representa a incorporação de esquemas avaliativos e disposições de comportamento a partir de uma situação socioeconômica estrutural, então mudanças fundamentais na estrutura socioeconômica devem implicar, consequentemente, mudanças qualitativas importantes no tipo de habitus para todas as classes sociais envolvidas de algum modo nessas mudanças. (SOUZA, 2004, p. 86)

Encontramos, nos trabalhos de Souza (2003), três variações, ou melhor, três níveis de desdobramentos do conceito de habitus: o primário, o precário e o secundário. Em nossa leitura, seria na construção desses desdobramentos conceituais que Souza (2004) operacionalizou teoricamente a noção de abandono social e seus desdobramentos, principalmente no que viria a ser um dos conceitos centrais de sua interpretação: o babitus primário. Com o conceito de habitus primário, Souza (2004) busca analisar os

[...] esquemas avaliativos e disposições de comportamento objetivamente internalizados e incorporados, no sentido bourdieusiano do termo, que permitem o compartilhamento da noção de "dignidade" no sentido tayloriano. É essa "dignidade", efetivamente compartilhada por classes que lograram homogeneizar a economia emocional de todos os seus membros numa medida significativa, que me parece ser o fundamento do reconhecimento social infra e ultra jurídico, o qual, por sua vez, permite a eficácia social da regra jurídica da igualdade e, portanto, da noção moderna de cidadania. É esta dimensão da "dignidade" compartilhada, no sentido não-jurídico de "levar o outro em consideração", denominado por Taylor (1986, p. 15) de respeito atitudinal, que tem de estar disseminada de forma efetiva na sociedade para que se possa vislumbrar concretamente a dimensão jurídica da cidadania e da igualdade garantida pela lei (SOUZA, 2004, p. 87).

Na proposta teórica de Jessé Souza, a ideia de um habitus primário (SOUZA, 2003) representa o que seria a base para o exercício de uma cidadania no Brasil contemporâneo. Assim, com esse conceito, teríamos categorizadas as "pré-condições sociais, econômicas e políticas do sujeito útil, "digno" e cidadão, no sentido tayloriano de reconhecido intersubjetivamente como tal” (SOUZA, 2003, p. 63). 
De forma mais precisa, com a ideia de habitus primário, o autor (SOUZA, 2003) remete a um conjunto de disposições que, no limite, diz respeito "[...] à presença da economia emocional e das pré-condições cognitivas para um desempenho adequado ao atendimento das demandas (variáveis no tempo e no espaço) do papel de produtor, com reflexos diretos no papel do cidadão, sob condições capitalistas modernas" (SOUZA, 2003, p. 67).

Seguindo de perto a construção da proposta teórica do autor, temos que esse conjunto de disposições, o habitus primário, representaria o marcador teórico e social do que Souza conceitua enquanto babitus precário e habitus secundário:

O que estamos chamando de "babitus secundário" tem a ver com o limite do "babitus primário" para cima, ou seja, tem a ver com uma fonte de reconhecimento e respeito social que pressupõe, no sentido forte do termo, a generalização do babitus primário para amplas camadas da população de uma dada sociedade. Nesse sentido, o babitus secundário já parte da homogeneização dos princípios operantes na determinação do habitus primário e institui, por sua vez, critérios classificatórios de distinção social a partir do que Bourdieu chama de "gosto". (SOUZA, 2003, p. 64)

Nesse sentido, temos que "a ausência dessas pré-condições, em alguma medida significativa, implica na constituição de um habitus marcado pela precariedade" (SOUZA, 2004, p. 67). O que Souza conceitua como babitus precário (SOUZA, 2003) diz respeito à incapacidade de desempenhar um papel em relação às demandas estabelecidas pela sociedade capitalista contemporânea, condição essa que resultaria da falta de uma economia emocional. Dessa forma:

O ‘babitus precário’ seria o limite do ‘habitus primário’ para baixo, ou seja, seria aquele tipo de personalidade e de disposições de comportamento que não atendem às demandas objetivas para que, seja um indivíduo, seja um grupo social, possa ser considerado produtivo e útil em uma sociedade de tipo moderno e competitivo, podendo gozar de reconhecimento social com todas as suas dramáticas consequências existenciais e políticas (SOUZA, 2003, p. 63).

Por isso, na busca por superar as leituras pautadas em um olhar "fetichista no progresso econômico" (SOUZA, 2003, p.51), construindo uma linha de reflexão sobre o quadro das desigualdades entre as classes e as frações de classes sociais no Brasil, a partir das ideias de babitus primário, precário e secundário, Souza aponta que:

Em sociedades periféricas como a brasileira, o habitus precário, que implica a existência de redes invisíveis e objetivas que desqualificam os indivíduos e grupos sociais precarizados como sub produtores e subcidadãos, e isso sob a forma de uma evidência social insofismável, tanto para os privilegiados como para as próprias vítimas da precariedade, é um fenômeno de massa e justifica minha tese de que o que diferencia substancialmente esses dois tipos de sociedades é a produção social de uma "ralé estrutural" nas sociedades periféricas. (SOUZA, 2003, p. 72)

Nesse sentido, temos que, para Souza (2012), o que representaria os desdobramentos do abandono social em relação à população não integrada à economia de mercado, praticada pelas classes dominantes e pelo Estado nacional, desde o princípio de nossa república, seria a formação de uma massa populacional marcada historicamente pelo desenvolvimento de um habitus precário (SOUZA, 2003). 
Assim teríamos que as dinâmicas sociais geradas a partir do abandono social resultariam na formação de uma população marcada pelo desajustamento em relação às demandas de uma economia moderna, decorrido da falta das predisposições psicossociais e das pré-condições cognitivas para desempenhar, no limite, o papel do cidadão em uma contemporaneidade capitalista. (SOUZA, 2012).

É por esse caminho teórico, construído a partir da ideia de abandono social e das variações do habitus, que Jessé Souza categoriza o que ele compreende enquanto uma ralé-estrutural (SOUZA, 2003), recolocando, no centro do debate, a questão da desigualdade entre as classes sociais e seus desdobramentos no Brasil contemporâneo. Segundo ele:

[...] o processo de modernização brasileiro constitui não apenas as novas classes sociais modernas que se apropriam diferencialmente dos capitais cultural e econômico. Ele constitui também uma classe inteira de indivíduos não só sem capital cultural nem econômico em qualquer medida significativa, mas desprovida, esse é o aspecto fundamental, das precondições sociais, morais e culturais que permitem essa apropriação. É essa classe social que designamos, em livro anterior a este, de 'ralé estrutural' (SOUZA, 2012, p. 25).

No desenvolver de sua proposta analítica, ele coloca que as "classes sociais não são determinadas pela renda - como para os liberais - nem pelo simples lugar na produção - como para os marxistas clássicos -, mas sim por uma visão de mundo 'prática' que se mostra em todos os comportamentos e atividades como esclarecida" (SOUZA, 2012, p. 45). Ou seja, a desigualdade social brasileira estaria ligada às condições sociais e culturais de existência, ou do desenvolvimento de um habitus primário (SOUZA, 2003).

Dentro dessa perspectiva e partindo da teorização acerca dos habitus, Souza tenta construir uma noção de classe social hoje, no Brasil, ao afirmar que "associar classe a renda é 'falar' de classe esquecendo-se de todo o processo de transmissão efetiva e emocional de valores, processo invisível, visto que se dá na socialização familiar, que constrói indivíduos com capacidades muitos distintas, como vimos mais acima". (SOUZA, 2012, p. 47).

Dessa forma, Jessé Souza se distancia das análises que associam as desigualdades entre as classes sociais apenas às questões de distribuição de renda e apresenta, como fator decisivo para essa desigualdade, a ideia de um "capital familiar" (SOUZA, 2012, p. 51) ao apontar para o fato de que "O 'segredo' mais bem guardado de toda a sociedade é que os indivíduos são produzidos 'diferentemente' por uma 'cultura de classe' específica”' (SOUZA, 2012, p. 22). Com isso, ele destaca:

A estrutura de classes produz estruturas familiares diferenciadas, compatíveis com a sua própria condição. Estruturas familiares que imitam a regularidade do "mundo", ou a falta desta, capazes de formar em cada pessoa, através das relações afetivas, a conformação necessária entre as suas expectativas individuais, seus sonhos e desejos, e as estruturas objetivas, as possibilidades concretas do mundo (SOUZA, 2124, p. 127).

Em sua elaboração teórica, Souza (2012) recoloca a centralidade da instituição família no processo de formação do que viria a ser uma cultura cívica integrada a uma sociedade de mercado e, ao pensar a relação entre o núcleo familiar e as demais instituições sociais, ele afirma: 
A família na modernidade se torna, em todas as classes, a instituição mais próxima dos corpos, a instituição que liga de forma mais intensa os indivíduos afetivamente. Portanto, cabe a ela uma dupla função, que outrora coube a outras instituições: reproduzir, em cada indivíduo - de forma durável e inconsciente - a ordem do mundo, ou seja, a dominação impessoal, que ultrapassa sempre os limites da própria família (SOUZA, 2012, p.127).

Sobre a centralidade da família para a produção e reprodução do que viria a ser o habitus primário (SOUZA, 2003), temos:

A família nuclear é uma regra moral, naturalizada como essência humana. Não possuíla é ser mutilado na própria noção de humanidade. Mas família nuclear, tal qual a conhecemos, longe de ser uma estrutura natural, é uma formação recente, moderna, e de uma classe específica: a burguesia (SOUZA, 2012, p. 125).

Desse modo, na busca por construir um olhar sobre a realidade social brasileira que visa ultrapassar os limites da ideia de um fetichismo no progresso econômico como único caminho para superação do quadro de desigualdade social, Souza (2012) demonstra que no Brasil:

[...] as raízes familiares de reprodução do privilégio de classe e o abandono social e político secular de classes inteiras, cotidianamente exercido pela sociedade como um todo em todas as suas práticas institucionais e sociais, são tornadas invisíveis para propiciar a "boa consciência do privilégio" econômico (das classes altas) ou cultural (das classes médias) e torná-lo legítimo (SOUZA, 2012, p. 25).

Por isso, podemos dizer que é a partir de uma pluralidade de babitus de classe, pautados ou produzidos a partir dos diferentes capitais familiares, que Souza (2012) olha para a questão das classes sociais no Brasil, principalmente para a questão das classes menos favorecidas. Estes, nos últimos anos, enquanto alvo de várias políticas públicas, vivenciaram diversas mudanças, chegando a ocupar, por algum tempo, um lugar no debate acadêmico do país que, entre outros tantos temas, também se debruçou sobre o que eles nomearam de a "nova classe média" brasileira.

Apresentaremos a seguir como Souza (2012) não refuta ou se coloca contrário ao fato de que essas mudanças foram importantes e de fato aconteceram para parte das classes menos favorecidas no país, aquela que, em decorrência do abandono social, pode ser caracterizada como portadora um habitus precário (SOUZA, 2003). Em contrapartida, sua análise destoa da tônica assumida pelo debate acadêmico nacional, ao tomar por base a proposta teórica criticada por Souza (2003), por pensar essas mudanças apenas a partir de questões econômicas como, por exemplo, a questão de acesso a mercado de bens de consumo.

\section{Sobre o capital familiar e a classe batalhadora}

Em seus escritos, Souza chama a atenção para a existência, em nossa cultura, de um tipo particular de violência simbólica, uma relação de violência em que "[...] o que fala nunca é a palavra, o discurso, mas toda a pessoa social" (BOURDIEU, 1983, p.167). É um tipo de violência que, como já vimos desde o processo de abolição, tem acompanhado a ralé-estrutural (SOUZA, 2003) e que pode ser percebida na forma de um "racismo de classe", que "não permite defesa porque nunca se assume como tal" (SOUZA, 2012, p. 49). Esse fato, segundo o autor, nos revela que "a violência simbólica perpetrada aqui age no sentido de negar toda a 'construção social do privilégio' como privilégio de classe, transmitido familiarmente de modo insensível e 'invisível' pelos mecanismos de socialização familiar”' (SOUZA, 2012, p. 48). 
Assim temos, no que diz respeito a essa chamada "nova classe média", que Souza (2012) entende que se trataria, na verdade, de uma nova classe trabalhadora, que seria proveniente do que ele categorizou enquanto uma ralé-estrutural (SOUZA, 2003), ou seja, se trataria de uma parcela dessa massa de pessoas marginalizadas socialmente pelos efeitos históricos do abandono social, que conseguiu adquirir aquilo que Souza (2003) conceituou como habitus primário.

No limite essa nova classe trabalhadora (SOUZA, 2012) seria uma parte da chamada ralé-estrutural (SOUZA, 2003), que conseguiu superar as consequências históricas do abandono social, habitus precário (SOUZA, 2003), e assim adquiriu as disposições necessárias, o habitus primário (SOUZA, 2003), para se adequar às demandas estabelecidas pela sociedade burguesa contemporânea e assim adentrou o mercado de trabalho formal no Brasil. Essa diferenciação entre os agentes sujeitos aos desdobramentos da relação de abandono social e aqueles agentes que conseguiram avançar diante dessas relações fica mais clara quando Souza (2012) afirma: "O que caracteriza toda classe trabalhadora é a sua "inclusão subordinada" no processo de acumulação do capitalismo em todas as suas fases históricas. O trabalhador, ao contrário da "ralé" e de todos os setores desclassificados e marginalizados, é reconhecido como membro útil à sociedade e pode criar uma narrativa de sucesso relativo para sua trajetória pessoal”. (SOUZA, 2012, p. 52)

Mas como explicar essa mudança de habitus? É aqui que Souza (2012) nos apresenta a ideia de capital familiar, pois o que de fato diferenciaria o que ele conceituou enquanto uma ralé-estrutural (SOUZA, 2003) e o que categorizou enquanto os batalhadores brasileiros (SOUZA, 2012) seria a diferença de acesso a um capital simbólico, ou seja, acesso

[...] às formas de lucro e de poder que assegura, só existe na relação entre as propriedades distintas e distintivas como corpo correto, língua, roupa, mobília (cada uma delas obtendo seu valor a partir de sua posição no sistema das propriedades correspondentes, ele mesmo objetivamente referido ao sistema das posições nas distribuições) e indivíduos ou grupos dotados de esquemas de percepção e de apreciação que os predispõem a reconhecer (no duplo sentido do termo) essas propriedades (BOURDIEU, 2013, p. 111).

Segundo Souza:

Essa é uma distinção fundamental em relação às famílias da "ralé" que estudamos em livro anterior a este. A família típica da "ralé" é monoparental, com mudança frequente do membro masculino, enfrenta problemas graves de alcoolismo, de abuso sexual sistemático e é caracterizada por uma cisão que corta essa classe ao meio entre pobres honestos e pobres delinquentes. É a classe vítima por excelência do abandono social e político com que a sociedade brasileira tratou secularmente seus membros mais frágeis. [...] Vários dos batalhadores são oriundos da "ralé" - ou da "elite da ralé", para a qual os fatores destrutivos puderam ser compensados de algum modo eficaz - e conseguiram a duras penas ascensão material e alguma dose de autoestima e de reconhecimento social (SOUZA, 2012, p. 50).

Assim temos que, a partir de uma crítica às correntes que buscam teorizar sobre as particularidades sociais do Brasil, tendo por base a ideia de uma possível superação da desigualdade entre as classes sociais via distribuição de renda, Jessé Souza, ao retomar o mote do abandono social juntamente com duas perspectivas teóricas contemporâneas, as de Pierre Bourdieu e de Charles Taylor, permite um grande avanço nos debates teóricos acerca da desigualdade social no Brasil, pois nos apresenta duas importantes categorias de análise, a ralé-estrutural (SOUZA, 2003) e os batalhadores (SOUZA, 2012). 
Porém, em nossa leitura, a tentativa de equacionar as diferenças entre esses dois grupos sociais ganharia um lastro explicativo maior se a segunda categoria, os batalhados (SOUZA, 2012), não apareceria condicionada por uma relação direta, com que Souza (2012) conceitua enquanto capital familiar, sobretudo porque esse capital simbólico é apresentado em uma relação direta com a ideia de uma família nuclear específica, pautada em um modelo burguês de núcleo familiar.

Percebemos também que isso foi possível a um capital muito específico que gostaríamos de chamar de "capital familiar" [...] chamamos esse conjunto interligado de disposições para o comportamento de "capital familiar", pois o que parece estar em jogo na ascensão social dessa classe é a transmissão de exemplos e valores do trabalho duro e continuado [...] a maior parte dos batalhadores entrevistados [...] possuem família estruturada, com a incorporação dos papéis familiares tradicionais de pais e filhos bem desenvolvidos e atualizados. (SOUZA, 2012, p. 50)

Mais especificamente, esse capital simbólico aparece atrelado à ideia de um núcleo familiar burguês, estruturado "com a incorporação dos papéis familiares tradicionais de pais e filhos bem desenvolvidos e atualizados" (SOUZA, 2012, p. 50). Isso se faz perceber também no momento em que ele categoriza como uma das características das famílias da ralé-estrutural a falta de um projeto pessoal, ou seja, a falta de um futuro, ou de um "pensamento prospectivo" (SOUZA, 2012, p. 51). "A capacidade de planejar a vida e de pensar o futuro como mais importante que o presente é privilégio das classes em que o aguilhão da necessidade de sobrevivência não as vincula à prisão do presente sempre atualizado como necessidade premente. A "ralé" é refém do "presente eterno", do incerto pão de cada dia e dos problemas que não podem ser adiados." (SOUZA, 2012, p. 51).

Ao levar em conta a importância das considerações e dos conceitos cunhados por Jessé Souza (2003; 2004; 2012), sobre as dinâmicas e as desigualdades sociais no Brasil, que, no limite, podem ser lidas enquanto uma construção decorrente de uma espécie de economia de capitais familiares, podemos refletir, de maneira exploratória, sobre os processos de engendramento e de legitimação desse capital simbólico específico, em uma tentativa de desnaturalizar a ideia de um modelo de família nuclear burguesa enquanto única matriz possível de disposições e práticas sociais adequadas à contemporaneidade.

Nesse sentido apresentamos um possível alargamento teórico diante das reflexões sobre as diferenças e as proximidades entre o que Jessé Souza categoriza, a partir de uma distinção de capitais familiares (SOUZA, 2012), enquanto uma ralé estrutural (SOUZA, 2003), e o que ele nomeia de batalhadores (SOUZA, 2012), assumindo como mediadora a existência de um capital simbólico ligado diretamente ao núcleo da unidade familiar.

Essa perspectiva é possível, sobretudo porque, por exemplo, encontramos, nos escritos de Robert W. Slenes (2011), apontamentos sobre as famílias cativas existentes no país, durante o ciclo econômico do café. Trata-se de famílias que foram, e ainda são, em sua maioria, vítimas do abandono social praticado pela sociedade nacional, mas há a possibilidade de se pensar esse núcleo familiar enquanto detentor de "um projeto de vida" (SLENES, 2011, p. 59). Segundo o autor: "O que emerge deste enfoque é a família como centro de "um projeto de vida". Essa família-projeto, entretanto, não configurava uma "brecha' camponesa que permitia uma pequena autonomia ao cativo [...] ao contrário, é um campo de batalha, um dos palcos principais, aliás, em que se trava a luta entre escravo e senhor e se define a própria estrutura e destino do escravismo" (SLENES, 2011, p. 59). 
Em nossa leitura, a construção teórica sobre a problemática das classes sociais no Brasil, apresentada por Souza $(2003 ; 2004 ; 2012)$ e que tem como princípio os desdobramentos de um abandono social, assim como a busca por um distanciamento daquilo que o mesmo apresenta como uma espécie de fetichismo em um progresso econômico, se coloca como um novo caminho para interpretar a questão das classes sociais no país. Souza não pensa

[...] a prática como uma relação mecânica, diretamente determinada pelas condições antecedentes e inteiramente redutível ao funcionamento mecânico de esquemas preestabelecidos, "modelos", "normas", ou "papéis", que deveríamos, aliás, supor que são em um número infinito, como são as configurações fortuitas dos estímulos capazes de desencadeá-los (BOURDIEU, 1983, p. 64).

$\mathrm{Na}$ busca por um maior distanciamento em relação aos paradigmas teóricos que entendem a questão da desigualdade social apenas por um viés econômico, Souza (2012) apresenta a necessidade de se adentrar no mundo das práticas sociais, tendo em vista que

[...] a prática é, ao mesmo tempo, necessária e relativamente autônoma em relação à situação em sua imediatidade pontual, porque ela é o produto da relação dialética entre uma situação e um habitus - entendido como um sistema de disposições duráveis e transponíveis, que, interligando todas as experiências passadas, funciona a cada momento como uma matriz de percepscão, de apreciação e de ações e torna possível a realização de tarefas infinitamente diferenciadas, graças às transferências analógicas de esquemas, que permitem resolver os problemas da mesma forma, e as correções incessantes dos resultados obtidos, dialeticamente produzidas por esses resultados. (BOURDIEU, 1983, p. 65).

Assim, quando pensamos sobre os desdobramentos do chamado abandono social (SOUZA, 2003), na busca por compreender as especificidades dos grupos sociais dominados no Brasil, nomeados por ralé-estrutural (SOUZA, 2003) e batalhadores (SOUZA, 2012), estamos diante de um modelo interpretativo que leva em conta as dinâmicas existentes entre as classes sociais, na medida em que

[...] as práticas não se deixam deduzir nem das condições presentes que podem parecer tê-las suscitado nem das condições passadas que produziram o babitus, princípio durável de sua produção. Só se pode explicá-las, portanto, com a condição de relacionar as condições sociais nas quais se constitui o habitus que as engendrou e as condições sociais nas quais ele é posto em ação [...] história incorporada, feita natureza, e esquecida como tal, o habitus é a presença operante de todo o passado do qual é produto: no entanto ele é o que confere às práticas sua independência relativa em relações às determinações do presente imediato. (BOURDIEU, 2009, p. 93)

Em nossa leitura, a contribuição de Souza $(2003 ; 2004$; 2012) para a interpretação das classes sociais no Brasil estaria na noção de capital familiar (SOUZA, 2012, p. 51), uma vez que ela permite pensar sobre uma multiplicidade de capitais familiares, responsáveis por gerar uma diversidade de práticas sociais, tendo em vista que o habitus, em sua esfera individual, atua enquanto "uma capacidade infinita de engendrar em toda a liberdade (controlada) produtos - pensamentos, percepções, expressões, ações - que sempre têm como limites as condições historicamente e socialmente situadas de sua produção. A liberdade condicionada e condicional que ele garante está tão distante de uma criação de uma imprevisível novidade quanto de uma simples reprodução mecânica dos condicionamentos iniciais". (BOURDIEU, 2009, p. 91). 
Por isso, para pensarmos a condição contemporânea desses chamados batalhadores (SOUZA, 2012), temos que ter em vista que, no interior de uma classe social, "o princípio das diferenças entre os habitus individuais reside na singularidade das trajetórias sociais, às quais correspondem as séries de determinações cronologicamente ordenadas e irredutíveis umas às outras" (BOURDIEU, 2009, p. 100). Nesse sentido, seria "tão verdadeiro quanto falso dizer que as ações coletivas produzem os acontecimentos ou que eles são seu produto. Na verdade, elas são produto de uma conjuntura, isto é, conjunção necessária das disposições de um acontecimento objetivo" (BOURDIEU, 1983, p. 76).

As contribuições de Jessé Souza representam um importante avanço junto à discussão sobre as questões de classe no Brasil contemporâneo. Suas propostas teóricas apresentam novos termos significantes para a construção do debate sobre as dinâmicas de classe no país, denunciando a necessidade de um distanciamento de visões que tentam enquadrar o brasileiro em um arranjo teórico pautado na ideia de um homo economicus (BOURDIEU, 1983).

\section{Considerações Finais}

Ao finalizarmos a reflexão aqui apresentada, destacamos que talvez um caminho para ampliação das discussões acerca dos desdobramentos do abandono social (SOUZA, 2003), que entrelaça as relações sociais em nosso país, desde o fim do século XIX, seria olhar para as práticas e para as estratégias de cada agente ou de cada grupo de agentes no interior das classes sociais. Isso porque, enquanto experiência social incorporada, "o habitus torna possível a produção livre de todos os pensamentos, de todas as percepções e de todas as ações inscritas nos limites inerentes às condições particulares de sua produção" (BOURDIEU, 2009, p. 91).

O fato de existirem historicamente distintos modelos de famílias no país remete a distintos capitais familiares, que, contextualizados em suas devidas conjunturas históricas, engendrariam práticas sociais diversificadas entre os membros de um mesmo grupo, ou, se preferirmos, de uma mesma classe social. É nesse sentido que um olhar praxiológico (BOURDIEU, 1983) talvez nos permita avançar, tendo em vista a necessidade colocada por Souza (2003) de superar a ideia de um progresso econômico como caminho para o fim da desigualdade de classe no país. Entende-se que um estudo praxiológico deve assumir como objeto,

[...] não somente o sistema das relações objetivas que o modo de conhecimento objetivista constrói, mas também as relações dialéticas entre essas estruturas e as disposições estruturadas nas quais elas se atualizam e que tendem a reproduzi-las, isto é, o duplo processo de interiorização da exterioridade e de exteriorização da interioridade. Este conhecimento supõe uma ruptura com o modo de conhecimento objetivista, quer dizer, um questionamento das condições de possibilidade e, por aí, dos limites do ponto de vista objetivo e objetivante que apreende as práticas de fora, enquanto fato acabado, em lugar de construir seu princípio gerador situando-se no próprio movimento de sua efetivação. (BOURDIEU, 1983, p. 47)

Dessa maneira, ao pensarmos praxiologicamente a relação entre as classes sociais, $\mathrm{O}$ capital familiar e a ideia de um abandono social no país, ampliaríamos o alcance explicativo de nossas análises, assumindo que, 
[...] para definir a relação entre o babitus de classe e o babitus individual (indissociável da individualidade orgânica imediatamente dada à percepção imediata - intuitus personae - e socialmente designada e reconhecida - nome próprio, pessoa jurídica, etc.), poder-seia considerar o habitus de classe (ou de grupo), isto é, o habitus individual na medida em que exprime ou reflete a classe (ou o grupo) como um sistema subjetivo, mas não individual de estruturas interiorizadas, esquemas comuns de percepção, de concepção e de ação, que constituem a condição de toda objetivação. [...] efetivamente, é uma relação de homologia, ou seja, de diversidade na homogeneidade que reflete a diversidade na homogeneidade característica de suas condições sociais de produção, que une os habitus singulares dos diferentes membros de uma mesma classe: cada sistema de disposições individuais é uma variante estrutural dos outros, na qual se exprime a singularidade da posição no interior da classe e da trajetória. (BOURDIEU, 2009, p. 99)

Por fim, pensar sobre o Brasil, tendo em vista todas as suas especificidades culturais, políticas e econômicas, sempre foi um desafio. Podemos dizer que, contemporaneamente, as contribuições de Jessé Souza são fundamentais para novas possibilidades de análises e entendimentos sobre as dinâmicas sociais brasileiras, pois apontam para um caminho que não se encontra preso às amarras de uma visão objetiva e economicista de nossa sociedade.

\section{Referências}

BOURDIEU, Pierre. Esboço de uma teoria da prática. In: ORITIZ, Renato (Org.). Bourdieu - Sociologia. São Paulo: Ática, 1983. p. 46 a 81.

BOURDIEU, Pierre. O Senso prático. Petrópolis: Vozes, 2009.

BOURDIEU, Pierre. Capital simbólico e classes sociais. Novos Estudos Cebrap, n.96, p. 105115, 2013.

DOSSE, François. História do estruturalismo, v2: o canto do cisne de 1967 aos nossos dias. São Paulo: Ensaios; Campinas:Editora da Universidade Estadual de Campinas, 1994.

FERNANDES, Florestan. A integração do negro na sociedade de classes. São Paulo: Globo, 2008.

NABUCO, Joaquim. O abolicionismo. Petrópolis: Vozes, 1977.

SLENES, Robert W. Na senzala, uma flor: esperanças e recordações na formação da família escrava: Brasil Sudeste, século XIX. Campinas: Editora da Unicamp, 2011.

SOUZA, Jessé. (Não) Reconhecimento e subcidadania, ou o que é "ser gente"? Lua Nova, n..59, p.51-74, 2003. . Disponível em: http://dx.doi.org/10.1590/S0102-64452003000200003. Acesso em: Acesso em: 05/nov/2020.

SOUZA, Jessé. A gramática social da desigualdade brasileira. Revista brasileira de ciências sociais. N. 54. 2004, p. 79 - 96. Disponível em: http://www.scielo.br/pdf/rbcsoc/v19n54/ a05v1954.pdf. Acesso em: 05/nov/2020.

SOUZA, Jessé. Os batalhadores brasileiros: a nova classe média ou a nova classe trabalhadora? Belo Horizonte: Editora UFMG, 2012. 